\title{
Cultural Competence Development, Critical Service Learning, and Latino/a Youth Empowerment: A Qualitative Case Study
}

\author{
Lucila C. Vargas ${ }^{\mathrm{a}}$ and Joseph Erbab \\ aSchool of Journalism and Mass Communication, University of North Carolina at Chapel Hill; bWilliam Allen White \\ School of Journalism and Mass Communications, University of Kansas
}

\begin{abstract}
As universities create service-learning programs, educators are experimenting with pedagogical approaches that enhance learning outcomes while benefiting communities. We present a qualitative case study of a radiobased, service-learning program, grounded in a Freirean foundation and aimed at developing the cultural competence and sense of citizenship of undergraduate students while empowering working-class high school Latino/a students. Undergraduate students benefited the most from the program; they enhanced their cultural competence skills, awareness of social issues, and sense of civic responsibility. Latino/a high school students who stayed in the program for at least a year developed self-confidence, self-esteem, and a sense of self-efficacy.
\end{abstract}

\section{KEYWORDS}

Adolescents; community radio; cultural competence; diversity in education; Latino/a; service learning; youth empowerment

Last week at Radio Latino, $\operatorname{Liz}^{1}$ (an undergraduate student) assisted Reyna (a Latina high school student) in hosting her show about el día de los muertos (All Souls' Day) and the 2012 elections. I think the teens really enjoyed exploring the history of this tradition ... I'm also glad the teens announced the polling places for this election and encouraged listeners to be informed and vote [...] I was excited to see the teens confidently (and sometimes loudly!) articulating their thoughts on controversial politics and recognizing each other's viewpoints. (Karen, undergraduate student)

In this vignette, an undergraduate student describes an emblematic event during the live production of a radio show that was the core of a service-learning/youth empowerment program, in which college undergraduate students worked with Latino/a high school students to produce the show. Radio Latino (RL) aimed to empower working-class Latino/a adolescents while simultaneously enabling college students to enhance their cultural competence and sense of citizenship. In this essay, we hope to shed light on thorny issues related to service learning, specifically with underserved Latino/a youth. We study the intersection between two seemingly unrelated trends that are transforming higher education: the wider acceptance that service learning has been gaining (Bollin, 2007) and the growing awareness of the need for student cultural competence development (Len-Ríos \& Perry, 2009). To this end, this essay is a qualitative case study of RL, a program that we created and implemented for 5 years (2009-2014) at a Southeastern public university (SPU hereafter).

Most definitions of service learning highlight that it is (a) a pedagogical approach integrating academic learning with service that meets authentic community needs, (b) intended to enrich the curriculum while fostering a sense of citizenship, and (c) accomplished through experiential learning and structured reflection (Carney, 2004; Sperling, 2007). John Dewey's (1938) philosophy is often considered the foundation of service learning, but Dewey paid little attention to power. By contrast, critical service learning, which highlights issues of power and oppression (Artz, 2001), is based on the philosophy of Paulo Freire. Both pedagogies are grounded in antifoundational epistemologies

CONTACT Lucila C. Vargas Icvargas@email.unc.edu School of Journalism and Mass Communication, University of North Carolina at Chapel Hill, 359 Carroll Hall, Chapel Hill, NC 27599, USA.

${ }^{1}$ We use pseudonyms to refer to all participants. 
and share many crucial tenets (e.g., dialogue and experiential learning, link between reflection and community action, and social change potential of education; Deans, 1999), but while Dewey advocated social reform, Freire promoted social transformation. The political commitment inherent in Freirean pedagogy makes it especially pertinent for scholars theorizing service learning with working-class racial/ethnic communities. Freire (1973) advocated action to transform conditions of oppression; an empowering educational practice, he argued, must be grounded in theory and committed to social justice. Freire offered an appropriate framework for RL because we sought to engage participants in social and cultural critique.

A central concept of Freirean pedagogy is praxis, which entails action that is inseparable from critical reflection (Freire, 1973). Reflection "is considered a core component of service-learning and one that enriches the process and differentiates it from other learning forms" (Kelley, 2012, p. 17). Many other authors have argued for the value of reflection (Bollin, 2007; Panici \& Lasky, 2002). Carney (2004), for example, said that:

A vital component of the successful service learning experience is reflection. The weekly journal is by far the most important tool for making potential volunteerism into the true mutual exchange undergirding the service learning ideology. When students are able to reflect on their work in the community, they are able to move beyond the disconnected mode of volunteerism to discover valuable lessons, both academic and personal. (p. 269)

We confirmed Carney's (2004) point, as it was through reflection that many RL participantsincluding us, by writing this essay-learned valuable lessons. However, we also confirmed what authors like Ash and Clayton (2004) and Hondagneou-Sotelo and Raskoff (1994) warned about: that poor-quality reflection may prevent students from probing their own assumptions and may even reinforce their prejudices and stereotypes. In service-learning programs with working-class Latino/a youth, the intersection of class and race/ethnicity is of utmost importance. However, while diversity and multiculturalism have been included in the curriculum, as Scatanburlo-D'Annibale and McLaren (2004) argued, "the manner in which 'difference' has been taken up within 'post-all' frameworks has tended to stress its cultural dimensions while marginalizing and, in some cases, completely ignoring the economic and material dimensions of difference" (p. 184). Striving not to ignore those dimensions, we adopted a conceptualization of cultural competence that embraces them.

Although a contested concept, recent scholarship conceptualizes cultural competence as a multidimensional and nonlinear process that involves cognition, affect, and behavior. Most authors recognize three dimensions: cultural awareness, cultural knowledge, and cultural skills, but Latino/a scholars Súarez-Balcazar et al. (2011) added a fourth dimension, cultural practice, which is defined as "experiencing other cultures and learning to appreciate diversity in society" (p. 5). They explained cultural knowledge as "learning about the cultural practices of specific racial or ethnic groups" and cultural skills as "developing professional practices and behaviors designed to improve service delivery to diverse populations" (p. 5). Notably, they underlined that cultural awareness requires "developing a critical view of cultural differences, people's experiences of oppression and marginalization, class differences, discrimination, racism, and becoming aware of one's cultural biases" (p. 5).

We begin the essay with a brief review of the literature on service learning in our field, media and journalism studies. Then, we present the study's method and describe RL. In the next sections, we discuss the extent to which RL served participants. This discussion is followed by a discussion on the ways in which it facilitated empowerment and the development of cultural competence and a sense of citizenship. Our goal here is not to conduct an educational evaluation; however, RL was both a service-learning program and a communication-for-social-change project, and case studies of these projects are inherently evaluative. Hence, we conclude with a more pointed examination of the program's limited success and its implications for policy and practice. The literature tends to be about successful programs, but reflecting on programs that only achieve limited success, such as RL, reveals important lessons. 


\section{Service learning in media and journalism studies}

The scholarship on media or journalism service-learning programs has been growing (Cohen \& Kinsey, 1994; Flourney, 2007), but studies paying attention to both service learning and community empowerment are rare and have focused on the benefits for students while overlooking the benefits to the community (Novek, 1999). While Panici and Lasky (2002) found that service learning was "beginning to become a vital part" of the curriculum (p. 120), they raised concerns about "productoriented service learning," which fails to establish meaningful connections with the community and deprives students of opportunities to reflect on their experience (p. 121). Critical educators have raised similar concerns about programs that see service as charity rather than as solidarity with those being served and that fail to challenge students to problematize social and cultural structures (Artz, 2001; Sperling, 2007).

\section{Method}

The qualitative case-study method is grounded in epistemologies that champion naturalistic inquiry and interpretive strategies that privilege lived experience as the data source. It has been used extensively in education (Stake, 1995), and as Reis (2010, para. 2) said, it "has proven particularly useful for studying educational innovations, evaluating programs, and informing policy." The method seeks to create a complete representation of the case examined, and it uses the power of story to capture thought and action while examining lived experience (Feagin, Orum, \& Sjoberg, 1991; Stake, 1995).

To ensure triangulation, we combined participant observation with other methods of data collection. First, we spent more than $800 \mathrm{hr}$ at the radio station and wrote numerous ethnographic notes (roughly, Author A met with students once a week for about $2 \mathrm{hr}$ during the course of 5 years; Author B did the same, but for 3 years). Second, we created an archive that consisted of the RL Facebook page, logs and attendance sheets, news articles, and videotaped and written comments by the students; the latter included 173 reflection papers written by undergraduate students. ${ }^{2}$ In RL's last five semesters, each undergraduate student completed nine 300- to 450-word reflection papers; these weekly assignments were graded and followed a three-part rubric that asked them to describe their service learning, connect it to course concepts, and explain how they benefitted from the experience. This type of rubric has been used at other universities for service-learning programs (De Leon \& Kirby-Stokes, n.d.).

In our analysis, we followed Emerson, Fretz, and Shaw's (2011) guidelines for processing ethnographic field notes, which are somewhat similar to grounded theory because they are based on constant comparison, coding, and memoing. By examining logs and attendance sheets, we produced a longitudinal record of all participants' involvement in RL. News articles about the program revealed what they considered to be important matters for them and for the Latino community. On the Facebook page, we examined online interactions among the teens to look for themes associated with efficacy and self-esteem. Similarly, we looked for such themes in news articles and in videotaped and written comments by teens and students; in the case of students, we also paid special attention to themes related to cultural competence development.

Given the richness of the 173 reflection papers, we employed Charmaz's (2006) approach to grounded theory and her coding advice. First we coded a few papers line by line (open coding); then we combined several codes into a larger one-for example, "talk," "speak," "tell," and "express" became subcategories of the broader category "voice," which was the most frequent. Subsequently, we related categories such as "voice" with other categories, such as "silence." Finally, we compared and contrasted categories and subcategories looking for relations between, for example, "silence" and "voice" and "express."

${ }^{2}$ SPU's Academic Affairs Institutional Review Board exempted our application for review, but Author A obtained oral consent from the students at the end of the semester to use their papers for research and promised confidentiality. 
This essay provides an etic/emic interpretation of $\mathrm{RL}$, as Author A taught the service-learning courses and Author B was the teaching assistant and coordinator of the radio show for the first 3 years. Although we had a very different class experience from that of the teens, we shared the migration experience with them and with many of the Latino/a undergraduate students. Author A came from Mexico with her 8-year-old son, who became a U.S. Latino teen. In her 20 years living in the SPU area, she has been involved with several community organizations serving Latino/as. Author B came to the United States as a young adult; he was born and raised in Corsica by a Corsican father and an immigrant White American mother.

This study has the strengths of the qualitative case-study method but also has its inherent limitations. Our participant-observer role in the research gave us complete access to sites, participants, and documents, but it presented its own drawbacks because we were vested in the program. Also, our position of power in relation to both teens and undergraduate students likely had an impact on the material that we collected. We did not use anonymous participant evaluations, because it is difficult to gather truly anonymous input from participants in a small program.

\section{The need for Radio Latino}

We created RL because we identified an unfulfilled demand for service-learning courses at SPU, a dearth of undergraduate opportunities for cultural competence, and a community need for empowerment projects for Latino/a teens. Globalization forces and Latino/a population growth have increased the need for Latino/a cultural competence at SPU. In 1990, our state had few Latino/a residents but has since experienced one of the nation's highest rates of Latino/a population growth. By the time we started the program in $2009,8.6 \%$ of the state's total population was Latino/a. It is projected that in 2017 , about $23 \%$ of all high school graduates in the state will be Latino/as-a $489.3 \%$ increase relative to 2007 , when Latino/as represented $5.3 \%$ of all high school graduates (SPU, 2007). However, the state has had a strong anti-immigrant climate (Nguyen \& Gill, 2010), and the interactions of most natives with Latino/as are often framed by the largely stereotypical media representations that still prevail in the local media (Paulin, 2011). These demographic changes have not been reflected at SPU and our school. When we started RL in 2009, 5.21\% $(N=937)$ of undergraduate students at SPU and $4.80 \%(N=40)$ at our journalism school were Latino/as, whereas Latino/a faculty represented only $2.90 \%(N=54)$ of all SPU faculty and $7.00 \%(N=3)$ at our school. By RL's last academic year (2013-2014), Latino/as represented 7.00\% $(N=1,299)$ of the undergraduate student population and 7.20\% $(N=56)$ of our school undergraduate students (Office of Institutional Research and Assessment, 2013). The share of Latino/a faculty was $3.73 \%(N=127)$ at SPU and $7 \%(N=3)$ at our school.

We carried out the program through a Latino/a Media Studies course and a Global Communication course, which usually had 20 to 25 juniors/seniors each. Time, resources, and logistic limitations made it difficult to offer service-learning opportunities to all students, so we opted to add a service-learning module. We accepted only 5 to 6 undergraduate students per semester into the module; Spanish-language skills coupled with genuine interest in community service and Latino/a culture became the criteria for selecting applicants. In the program's 5 years, 48 undergraduate students and 3 graduate assistants participated in RL and many others turned to it to complete assignments from other classes. Out of the 48 undergraduate students, $44(92 \%)$ were women, 22 (45\%) were White, 16 (33\%) were Latino/as, 8 (18\%) were African American, and 2 (4\%) were Asian American. When compared with SPU's overall student population-which, during the 5 years, was made up of about $60 \%$ women and $5.21 \%$ to $7 \%$ Latino/a-it is clear that RL predominantly attracted women and Latino/as. Some undergraduate students were the first in their families to go to college, but most came from middle-class or upper middle-class families.

We wanted a flexible program that could respond to a dynamic context; therefore, the way we implemented RL evolved throughout the years. In the first year (2009-2010), we partnered with "Pa'lante," a small nonprofit founded in 2003 by community activist Laura (last name withheld) who 
was running an afterschool empowerment project for Latino/a teens. In 2005, "Pa'lante" started to produce a weekly radio show on a community radio station that was within walking distance of the SPU campus. At the time, Pa'lante was the only local opportunity offered to Latino/a youth, and thus, it was our only choice for a community partner. However, due to lack of resources, Pa'lante closed down in the summer of 2010. Given high undergraduate demand for service learning and the increasing need for afterschool programs for Latino/a youth, we decided to take on the role previously played by Pa'lante. Consequently, from 2010 to 2014, we ran both the service-learning program and the youth empowerment project.

\section{The afterschool project of Radio Latino}

The program's Freirean approach called for a focus on empowerment, which we sought to facilitate among the teens by enabling them to improve their media literacy, interpersonal communication skills, and cultural competence in U.S. mainstream culture. A related goal was to inspire them to consider college and possibly careers in media and journalism. A total of 41 teens participated in RL for at least one semester. In addition, many others occasionally attended the show, probably because it was a safe space for youth who often felt ostracized at school (de los Ríos \& Ochoa, 2012; Martínez, Cortez, \& Saenz, 2013). All teens came from immigrant families; about two thirds had immigrated as children or young adolescents and the rest were born in Puerto Rico or the continental United States. We did not inquire about citizenship or residency, but many immigrant teens talked about their undocumented status. Reflecting the area's demographics, their origin/ancestry was predominantly Mexico and El Salvador. Although in terms of numbers, the gender difference was negligible ( 21 women vs. 20 men), the tendency was for women to remain in the program for longer periods than men. While many men attended for only one semester, many women attended for 1 year or even 2 years.

Meeting the needs and aspirations of both teens and undergraduate students presented numerous challenges, such as fostering the authentic relationships that form the basis of an effective, critical service-learning program (Mitchell, 2008). By the 2nd year, we had learned that pairing up one teen with one undergraduate student, who served as the teen's "coach," was an effective strategy for enabling authentic relationships. From Pa'lante, we inherited a collaboration with two local high schools to promote the afterschool project and its radio show and to ensure that the teens received community-service credit hours required for their graduation. This was the only incentive offered to them. While the high schools did not act as traditional community partners of service-learning programs, ${ }^{3}$ they did provide space for the weekly 1 -hr meetings that each undergraduate student was required to hold with his/her assigned teen.

The teens' life experience was very different from that of most of the undergraduate students. As part of a labor diaspora, the teens were vulnerable to the injuries of both race and class oppression. Their community was home to highly educated people, supported by a labor force largely composed of immigrant working-class Latino/as; many of the parents had little formal education, and even the more educated parents had to work as maids, bussers, handymen, and construction workers. The teens suffered constant microaggressions and felt they did not belong in the privileged local schools. For example, Elisse, an undergraduate, wrote about Camila, a teen: "She told me that even though she is a U.S. citizen by birth, she feels she doesn't belong here. Looking around the high school during our meeting, she said she knows she's different and doesn't fit in with all the students there." $\mathrm{RL}$ aspired to become a space of belonging.

\footnotetext{
${ }^{3}$ Usually, service-learning programs create a collaboration between an academic institution and a community, often through nongovernmental organizations, $\mathrm{K}-12$ schools, or government agencies.
} 


\section{The 'Radio Latino' show}

RL's core was the production of the "Radio Latino" radio show. It was the only Latino/a youth radio show in the state and among a handful of similar shows in the nation. It aired in Spanish every Friday from 5 p.m. to 6 p.m. Although the community station's low power frequency (approximately a 3.5-mile radius) limited the show's broadband reach, it was also streamed live through the station's Web site. Streaming was crucial because young Latino/as have adopted mobile technologies wholeheartedly, especially for listening to music (Korzenny, 2012). The show's Facebook page was also an effective means to communicate with the teens and with the audience; by the last semester of RL's operation, it had 651 followers, the majority of whom were Latino/a children and teens. The station allowed us to produce the show in its facilities for an annual \$120 underwriting fee. Our annual operating budget averaged about $\$ 2,000$, which came from our school and from small grants from SPU's service-learning office.

A typical show aired six to eight songs, three to four local news bulletins and announcements, shout-outs, and a 25-min guest interview. The teens chose the interview topics and favored issues related to immigration, sexuality and reproductive health, higher education, music, mental health, and Latin American celebrations. The show also addressed media, poetry, visual arts, high school life, Latino/a history, financial education, and domestic violence topics. The following vignette from Chiara, an undergraduate student, gives a better sense of the scene at the station:

Last Friday's RL show we had two guests from Planned Parenthood's program for teens. I thought the show was very engaging and our teens really jumped at the opportunity to ask the teen [from Planned Parenthood's youth group] questions related to healthy relationships, safe sexual care, and preventive care [...] However, I do think that overall the show was a little messy in terms of production and the teens weren't completely on top of everything - transitions from music to the interview were a little rough and the volumes kept being an issue.

The vignette hints at the overall enjoyment that the experience most often aroused and reveals the show's informality. Chiara's criticism was expressed by other undergraduate students too. Yet, RL's broad goals were achieved through this messy production process rather than through its media product. RL was process radio; process media is a strategy used to accomplish empowerment goals in which the production process is more important than its product because it is a space for developing critical consciousness (Kawaja, 1994). Anecdotally, we learned that the target local Latino/a youth audience was aware of the show, but we lacked solid evidence of who actually tuned into the program. Audience research is rare among community stations because the companies that measure audiences are not interested in noncommercial radio (Conti, 2011). We only received occasional callins, but teens received texts from friends and family. Some texts came from abroad, and teens aired their greetings to loved ones listening in Mexico.

We sketch the activities of each teen-undergraduate dyad in Table 1. They met twice a week, once at the station during the show and a second time at a place and time of their own choice. As mentioned, most often, they met at the teen's high school during lunch or study periods. Each dyad was responsible for producing two shows during the semester, and the undergraduate student's grade reflected the shows' quality.

Table 1. Activities of each teen-undergraduate dyad.

\begin{tabular}{|c|c|c|}
\hline & During the radio show & During the week \\
\hline Teen & $\begin{array}{l}\text {-Hosting and coproducing two shows, DJ (at } \\
\text { times) }\end{array}$ & $\begin{array}{l}\text {-Thinking about possible topics and } \\
\text { interviewees Selecting music }\end{array}$ \\
\hline Undergraduate coach & $\begin{array}{l}\text {-Acting as executive producer of two shows per } \\
\text { semester } \\
\text {-DJ (at times) } \\
\text {-Coaching his/her assigned teen on radio } \\
\text { production }\end{array}$ & -Writing weekly reflection papers \\
\hline $\begin{array}{l}\text { Teen-undergraduate } \\
\text { dyad }\end{array}$ & -Coproducing show (two per semester) & $\begin{array}{l}\text {-Meeting } 1 \mathrm{hr} \text { to plan show and work on teen's } \\
\text { homework }\end{array}$ \\
\hline
\end{tabular}




\section{Developing cultural competence}

The four dimensions of cultural competence-cultural awareness, cultural knowledge, cultural skills, and cultural practice-are not mutually exclusive and do not represent a linear progression in the development of a person's competence, as learning in these dimensions can occur simultaneously. For instance, producing the show allowed participants to acquire cultural skills because they were "developing professional practices and behaviors designed to improve service delivery to diverse populations" (SúarezBalcazar et al., 2011, p. 5). Cultural practice, previously defined as "experiencing other cultures and learning to appreciate diversity in society" (Suarez-Balcazar et al., 2011, p. 5), also took place through the production of the show during which undergraduate students-and to a lesser extent, teens-were learning more about Latino/a culture (cultural knowledge) and becoming more culturally aware. Indeed, the development of each of the dimensions occurred throughout the various activities of RL.

Separating the four dimensions from each other is problematic, but we do it in Table 2 for analytical purposes. This table provides examples of the cultural competence learning outcomes that we sought; however, it is by no means comprehensive, as we strived to create an environment in which all participants-including us-could learn from each other. For example, Latino/a middleclass undergraduate students learned from teens about being a working-class Latino/a adolescent, Non-Latino/a undergraduate students learned about being a Latino/a and about being a first/secondgeneration immigrant. Teens learned from undergraduate students about being middle-class and about being a college student; from the Non-Latino/a undergraduate students, the teens also learned about being from ethnic/racial groups different from their own. We learned how to become better service-learning teachers and how to facilitate youth empowerment.

\section{Learning and citizenship}

Learning course concepts was the easiest kind of learning to observe in class discussions and written comments: "It's easy to forget what you had to learn for an exam, but I won't forget the bonds that I made with my classmates, the teens, and the instances when I experienced course concepts firsthand," said Kate. Another undergraduate student, Jessica, wrote: "Listening to Paulina talk so openly about her feelings as a Latina in the U.S. really made me understand firsthand the struggles Latino/as

Table 2. Cultural competence learning outcomes of Radio Latino's critical service-learning program for university students (undergraduate students) and Latino/a high school students (teens).

\begin{tabular}{|c|c|c|c|c|}
\hline Learning Outcomes & Cultural awareness & Cultural knowledge & Cultural skills & Cultural practice \\
\hline $\begin{array}{l}\text { Teens \& undergraduate } \\
\text { students }\end{array}$ & $\begin{array}{l}\text {-Learning about Latino/a } \\
\text { history of oppression and } \\
\text { marginalization } \\
\text {-Exploring how media } \\
\text { shape perceptions of } \\
\text { Latino/as }\end{array}$ & $\begin{array}{l}\text {-Learning about } \\
\text { Latino/a heritage and } \\
\text { traditions } \\
\text {-Learning about } \\
\text { Latino/a contemporary } \\
\text { cultural production } \\
\text {-Researching interview } \\
\text { topics relevant to } \\
\text { Latina/os }\end{array}$ & $\begin{array}{l}\text {-Producing a Spanish- } \\
\text { language radio show } \\
\text {-Developing/honing } \\
\text { Spanish-language } \\
\text { skills }\end{array}$ & $\begin{array}{l}\text {-Participating in } \\
\text { shared cross-cultural } \\
\text { experiences } \\
\text {-Developing close } \\
\text { cross-cultural } \\
\text { relationships }\end{array}$ \\
\hline Teens only & $\begin{array}{l}\text {-Learning about class and } \\
\text { ethnic life worlds different } \\
\text { from their own } \\
\text {-Exploring college campus } \\
\text { life }\end{array}$ & & $\begin{array}{l}\text {-Honing English- } \\
\text { language skills }\end{array}$ & $\begin{array}{l}\text {-Immersing } \\
\text { themselves in the } \\
\text { local Latino/a culture }\end{array}$ \\
\hline $\begin{array}{l}\text { Undergraduate students } \\
\text { only }\end{array}$ & $\begin{array}{l}\text {-Learning about Latino/as' } \\
\text { experiences } \\
\text {-Reflecting on their own } \\
\text { experiences } \\
\text {-Becoming aware of } \\
\text { inequalities }\end{array}$ & & & \\
\hline
\end{tabular}


face in defining their personal citizenship and identity here. Citizenship, like Chavez points out, is more than a legal status in a state." She was referring to Chavez's (2008) discussion of the current destabilization of the concept of citizenship, which is an idea that undergraduate students often find impenetrable.

The program sought to foster a sense of citizenship by promoting undergraduate students' awareness of the social issues faced by Latino/a youth, a feeling of personal responsibility regarding such issues, and a desire to contribute to solve social problems. Making the connection between what Mills (1959/2000, p. 8) called "the public issues of social structure," which we studied in the classroom, and "the personal trouble of milieu," which they experienced through their service learning, seemed difficult at first for undergraduate students, but by midterm, most reflection papers showed an enhanced awareness and sense of citizenship. Liz, for example, described her efforts to enable Julia, her teen partner, to gain self-confidence:

\begin{abstract}
My discussion with Julia during mentoring this week gave me a greater understanding of how important it is to have Latino/as represented in the media. As we talked about some of her strengths and weaknesses, both in and outside of the classroom, Julia expressed her lack of confidence in her voice [...] I am so happy that she is participating in RL as I think that the show will provide her with an opportunity to share her opinions in a more comfortable environment. I encouraged her during our mentoring to really take initiative during the next show [...] Latino/as need to be represented in the media because it may be the only way they can gain confidence in their voice. People like Julia need to hear others similar to them express their views on a national, or at least local stage so that they can be assured that they are not alone, or wrong in what they believe.
\end{abstract}

Liz made an insightful connection between Julia's lack of confidence in her voice and the near absence of Latino/a voices in the media. Although this near absence has long been identified by scholars, recognized by media organizations, and denounced by Latino/a rights activists, many undergraduate students struggled to understand its significance. For Liz to recognize the local effects of the lack of media representation and her own civic duty to do something about it struck us as no less than remarkable.

\title{
Empowerment
}

Renato Rosaldo and other Chicano scholars have used the term "cultural citizenship" to refer "to the right to be different (in terms of race, ethnicity, or native language) with respect to the norms of the dominant community, without compromising one's right to belong" (Rosaldo \& Flores, 1997, p. 57). Cultural citizenship is deeply empowering, and we observed evident expressions of a new sense of cultural citizenship. Indeed, when asked why she participated in RL, Amanda, a teen, said: "Every time you learn something new and, as a Latina, in the community, sometime you forget, things about your own country ... it teaches something new about, your own, culture? And help your community too." The learning of Latino/a culture that Amanda articulated has been called "retro-acculturation" (Chattaraman, Rudd, \& Lennon, 2005). Latino/a undergraduate students often went through a retroacculturation process too. For example, Henry wrote:

Before I came to SPU, my Latinidad was almost none existent [sic]. The only thing that showed it was the color of my skin. Being here [at SPU] exposed me to many students from Latin America and South America. But RL was the best exposure I could ask for. Being able to hang out with Latino/as every week. Talk about Latino issues, listening to Spanish-language music and practicing my Spanish has increased my cultural competence [...] I have never been exposed to my culture like this and I want more.

We had not envisaged such profound examination of self. When we launched RL, its empowerment potential for the teens was evident for us, but we had not fully considered the empowerment potential for Latino/a undergraduate students. Another example of empowerment is illustrated by the experiences of Jason and Teresita, two teens who participated in RL for more than 2 years. When they joined, they were especially shy. In the following excerpt, Ashley, an undergraduate, describes Jason's transformation while interviewing a Latino/a poet: 
Jason never usually talks during the radio show, but he took the lead this [sic] show and ran it. I've never seen anything like it. He started off the interview talking about how strong and influential [the poet's] lyrics were, and how he related to them. And the coolest thing Jason shared a lot of himself on the air [...] also when [the poet] was performing, Jason was pumping and grinning from ear to ear like he respected everything [the poet] was saying. I feel like Jason not only conquered his fear of speaking on air, but he found a role model that he would be able to look up [sic] the rest of his life.

The excerpt displays Ashley's care and dedication for Jason and the joy she felt in witnessing his transformation. Transformations such as Jason's were unusual, but not unique. The following excerpt comes from the form that another teen, Teresita, needed to submit to her high school to earn community-service credit hours:

[RL] is important to me because ever since I joined to be a part of RL I have become more confident and take chances now with speaking out with new people. We write down questions to prepare ourselves, so when we interview the speaker we can find out things that interest us the youth. We also play songs (mainly in Spanish) that people request, anybody from the community or that listen [sic] to us on Friday 5 p.m. to 6 p.m. can call in and say what they want, discuss a topic that's important in our society/community or request a song (as long as what they say is appropriate, we put it on the air). The [high school] students that attend the radio [show] also get help from the college students that go and help out on the radio. Everyone interacts and become $[$ sic] friends quickly. It's a great way to get to know/meet new people and experience new things.

As Teresita wrote, RL enabled her personal growth. Years later, Author A has seen how Teresita, who now works at a local supermarket to support her higher education, confidently addresses shoppers over the loudspeaker. Some Latino/a undergraduate students also mentioned this benefit. For example, Karina was particularly shy, and she said that "people" were "always surprised" when she mentioned that she was a radio host. She added: "I have learned a lot about not being afraid to try new things and to go directly and give everything into the radio show. It honestly is the highlight of my week. This past Friday I was not having a good day, but after the show I honestly felt a sense of self-worth." Karina was one of the few undergraduate students who participated in RL for two semesters.

Mitchell (2008) noted that "critical service-learning programs encourage undergraduates to see themselves as agents of social justice and use the experience of service to address and respond to injustice in communities" (p. 51). Accordingly, we challenged undergraduate students to find viable solutions to social injustices faced by the teens. Many rose to the challenge. For example, they often wrote about their efforts to empower the teens to gain self-confidence and assisted several teens, whose parents have little formal education, in completing their college applications or even to obtain funding for their future education. On one occasion, undergraduate students helped a teen whose house had burned down, due to the owner's poor maintenance, to raise money and acquire household items. Through such relational experiences, undergraduate students confronted palpable instances of structural inequality, which enhanced their class awareness.

Many teens seemed to believe that by producing the radio show, they were empowering their community. Take for example the laconic response of Emilio to the question "How is your service important?" in the community-service form that he needed to submit to his high school: "Well, there isn't a lot of Latino radio stations in public intretament [sic]." Another teen, Itzel, also mentioned the lack of Latino/a voices in mainstream media and went a step further as she expressed her desire to become a reporter: "I want to be a reporter," she wrote in a scholarship application, "and use my talents and knowledge to help immigrants' voices be heard. The media are powerful tools; by being a reporter I can show the world that Latino kindness, hard work, and determination contribute to the United States." Itzel was awarded the scholarship and went to college. Despite these triumphs, however, we came up short of meeting the teens' needs. 


\section{On (not) meeting the teens' needs}

The dyad strategy fostered authentic relationships, but it also created its own challenges because what many teens needed the most was psychological counseling. Consider Freddy's response to the question of what he liked about RL: "it's fine, fine, 'cause you get to learn different things every time, like, uh, like when we learned about depression and stuff like that ... things that get you through life." Getting through life was not easy for the teens. Not only were they navigating adolescence, but they were also subjected to huge stressors under the state's anti-immigrant climate (Nguyen \& Gill, 2010). Consequently, they carried multiple psychological burdens that they sometimes unloaded on their coaches. Most undergraduate students, including Latino/as, were shaken by the information they received. For instance, Ofelia wrote several times about the depression that her teen partner was battling: "[She] worries me ... some of her comments are heartbreaking. I feel that she is going through a difficult time and she does not know the resources that can help her." Later in the semester, Ofelia further observed:

Personally, I feel that I'm a lot closer to my teen. She has opened up so much to me, which is a good and a bad thing. I'm glad that she has, because that means that I'm doing something right and that she trusts me. At the same time I feel that there is so much more that I could be doing to help her and sometimes I don't know how to help her out because right now she's going through so much.

We shared Ofelia's sense of helplessness. We tried to deal with this challenge by relying on our network of counselors and social workers, but it became clear that we needed a more effective strategy. Moreover, we suspected that some undergraduate students felt that sharing with us what the teens confided in them amounted to a betrayal. Angelena, for example wrote: "One of the [high school] students I work closely with has made me feel that I'm truly an important part of his life. He confides in me. He tells me what is troubling him, the difficulties he faces in school and even his personal life, and I try to help him as best as I can." Angelena was referring to a 15-year-old boy who was deeply worried because his girlfriend was pregnant. Unaware of the situation, we realized it when he announced, on the air, that he was going to be a father! The event revealed a key problem, which was that we were insufficiently preparing undergraduate students for their roles. They were required to attend an orientation session taught by the school district's volunteer coordinator. Author A taught a second orientation session, and the time dedicated to help the undergraduate students become aware of what they might encounter, especially in terms of psychological problems, increased every year. Each situation was unique though, and we never met this challenge. Reflecting on the semester's last show, Bethany, an undergraduate, wrote:

\footnotetext{
For some reason, completing the last show reminded me of the lecture we had on ambiguous loss. ${ }^{4}$ I realized that the ambiguous loss discussed in class referred to immigration, relocation, and transnationalism, but it can be applied to the show as well. Each semester, returning teens get a different mentor, thus having to experience the separation from their previous mentor. I wonder how they feel? How does it feel to form a connection with someone, just to see them leave after 10 weeks?
}

Bethany pointed out possible unintended consequences for the teens that were created by the dissonance among the three cycles under which RL operated: SPU's semester cycle, the high schools' academic-year cycle, and the afterschool program's year-round cycle. Although most undergraduate students expressed a desire to participate for a second semester, only eight actually did it and none ever committed to serve as a coach during the summer. The dissonance contributed to teen attrition and poor attendance. It took the constant presence of an encouraging adult or a teen leader to convince teens to attend regularly. We lacked resources to keep that presence. We attempted, unsuccessfully, to enlist parents. ${ }^{5}$ We tried to increase the support we enjoyed from high school teachers and social workers, but their multiple responsibilities prevented them from helping us. There were many other obstacles beyond our control: One was lack of

\footnotetext{
4"Ambiguous loss" refers to a concept introduced by Pauline Boss (1999) to talk about losses that, as opposed to complete losses such as a death in the family, are ambiguous. Examples include missing children, patients with Alzheimer disease, and migration loss.

${ }^{5}$ It is well documented that for a variety of reasons, most working-class Latino/a parents do not participate in school and afterschool programs.
} 
transportation, which is one of the most common problems for Latino/a youth programs, and another was the teens' waged work, fueled by their need to help their family as well as by their desire for the expensive electronic gadgets that their more affluent classmates had.

\section{Conclusion and implications for practice and policy}

An important goal of this article is to assist other educators in their community-engaged practice. Therefore, even though we had not aimed to perform a formal educational evaluation, we conclude by reflecting on the lessons we learned that could be beneficial to other service-learning programs. Because RL's youth empowerment component was a communication-for-social-change project, we turn to the field of communication for social change to assess RL's overall accomplishments and provide indicators other programs can also use for assessment or even conceptualization purposes. The following items stand out in this literature: (a) program impact; (b) attractiveness for the intended beneficiaries; (c) cost-benefit and creative use of existing resources; (d) longevity, sustainability, and scalability; and (e) design and theoretical soundness (McAnany, 2012; Unwin, 2009).

Program impact is generally considered the most important indicator. As our analysis showed, the teens and undergraduate students who benefitted the most were those who participated for more than one semester, which points out the need for long-term programs. For most of the 48 participating undergraduate students, RL provided an unusual opportunity for developing cultural competence and enhancing class awareness and sense of citizenship. Meeting the teens at their high schools and interacting with them during the radio show helped undergraduate students advance their cultural skills and enhance their awareness of social issues and their feeling of civic responsibility. This high level of learning, however, did not happen until we incorporated well-structured reflective writing. According to Kelley (2012), "reflection is considered among the most prolific of service-learning best practices" (p. 23, italics in original). de los Ríos and Ochoa (2012) said that in their program, "providing discussion and writing opportunities for students to critically reflect on the process of collaboration and their own roles enabled personal growth" (p. 279). As previously discussed, without critical reflection, service learning may actually reinforce prejudices. For example, during the first semesters of RL, most undergraduate students viewed their service learning as a form of charity and failed to engage in critical analyses of the societal arrangements that kept the teens disadvantaged. Most believed they were "helping" the teens, but they failed to see the benefits they themselves were obtaining. The stronger emphasis on rigorous reflective writing that we incorporated in the last semesters helped them see their service not as charity, but as advocacy. This emphasis, however, required the teaching-learning of reflective writing, which is a skill that few undergraduate students learn at SPU. Unfortunately, such additional teaching contributed to the discontinuation of the program because it demanded extra time from Author A.

Regarding the impact of RL on the teens, the results were mixed. Teens who stayed in the program for at least a year developed self-confidence, self-esteem, and a sense of self-efficacy. But even less persistent teens benefitted in at least one of the following ways. They enjoyed a space of belonging, a safe space to have fun. They acquired media literacy skills by learning "hands-on" how a radio show was produced and aired, which allowed them to demystify media. They improved their interpersonal communication skills by learning to conduct on-air interviews and engage in conversations with people beyond their narrow social milieu. They learned about topics that concerned them, such as immigration, sexuality, and education. They enhanced their cultural competence through their relationships with Non-Latino/as as well as with middle-class Latino/as. They bettered their resumes and obtained the community-service credit hours that they needed to graduate. And, significantly, they gained access to a medium that enabled them to have a social voice. Talking about the value of an Australian radio show somewhat similar to our show, Podkalicka (2009) said that "the distinctiveness of YouthWorx's approach lies in the way the project seeks to extend its public intervention ... towards an empowered social voice produced by technologies of community youth radio" (p. 567, italics in original). Furthermore, part of RL's impact was its symbolic value. At a time 
when states such as Arizona were banning books on cultural diversity and dismantling Latino/a Studies programs, RL sent the message that learning about Latino/a culture was important. The beneficial impact of RL on many undergraduate students can also be seen in the relaunching of the radio show. Although RL as a service-learning/youth empowerment program ended, the RL radio show has been relaunched by SPU Latino/a undergraduate students, who, led by a former participant, organized themselves through the university-wide Latino/a student organization. They plan to include Latino/a teens, but this most challenging aspect of the program has not happened yet.

The program's attractiveness for the intended beneficiaries is another important indicator. Recruiting undergraduate students was easy, as there were more interested undergraduate students than we could properly serve using Freirean pedagogy, which requires sustained dialogue between educator and educatee. However, teen recruitment and attendance was an overwhelming challenge. We faced factors beyond our control (e.g., lack of transportation), offered few incentives, and, most critically, failed to address the teens' frustration with having a new coach every semester and none during the summer. The college courses were not offered in the summer, but to keep teen and audience interest alive, the show had to be aired year-round. The first three summers, we volunteered to run RL. The fourth summer, we hired an undergraduate student to produce the show, but teen interest diminished. By the fifth summer, we decided to discontinue the program.

Most disappointing was that we failed to devise an effective strategy to deal with the mental health issues many teens were facing. Although RL was not a mental health program, these issues are unavoidable when working with working-class Latino/a youth. Neglecting to respond, even minimally, to this difficult challenge betrays the reciprocity requirement of service learning. A related issue was RL may have implicitly rendered teens and their families as failures because we aimed to instill in the teens a desire to go to college, which implies a middle-class definition of success. RL may have also raised unrealistic expectations. For many teens, attaining a college education would have been a tremendous feat. Some were undocumented, which meant paying the high tuition fees charged to international students; most were struggling academically, which hindered their scholarship opportunities; and some of the young women faced more subtle pressures. Breanna, for example, often talked about the arguments she had with her uncles, who insisted that college was not for women. RL's youth empowerment project may have been more effective if its definition of success had been more reassuring of working-class identity. But because RL also had a servicelearning component for college students, run by a college professor and her graduate students, we failed to problematize, as Freire would have advised, our own middle-class assumptions.

Other indicators of program success are longevity, cost-benefit ratio, creative use of existing resources, sustainability, and scalability. RL operated for 5 years with very limited funding by creatively using existing resources, but it was neither sustainable nor scalable. Communicationfor-social-change scholars have noted that without a champion at the top of a parent institution, projects seldom succeed (McAnany, 2012; Unwin, 2009). RL did not enjoy a champion at SPU, which meant it had insufficient funding and depended on only one professor and graduate students. This fact confirms the conclusion of authors like Panici and Lasky (2002), who stressed the common lack of institutional support and enabling policies for service learning. As Butin (2006) contended institutional prioritization and resource allocation most often hinder the success of programs because service-learning has "minimal exchange value (e.g., tenure and promotion prioritization)" (p. 475). To be sustainable, these programs need to be recognized in tenure and promotion policies and need to be supported by institutional resources, especially in the form of a course release for faculty implementing the programs.

The last indicators of success are program design and theoretical soundness. We learned by doing and continuously adjusted our original design, which certainly had many flaws but also had an inherent flexibility that made RL's limited success possible. RL had an explicit Freirean foundation guiding its development and formative assessment; it also had a robust theoretical construct of cultural competence. Freirean pedagogy and Suarez-Balcazar et al.'s (2011) conceptualization of cultural competence, with its emphasis on social justice, provided a solid framework that other 
educators may find valuable. Public universities have an obligation to serve their communities. Engaged teaching-learning with underprivileged youth is not only a matter of social justice, but also a matter of sound institutional policy.

\section{References}

Artz, L. J. (2001). Critical ethnography for communication studies: Dialogue and social justice in service-learning. Southern Communication Journal, 66, 239-250. doi:10.1080/10417940109373202

Ash, S. A., \& Clayton, P. H. (2004). Articulated learning: An approach to guided reflection and assessment. Innovative Higher Learning, 29, 137-154. doi:10.1023/B:IHIE.0000048795.84634.4a

Bollin, G. G. (2007). Preparing teachers for Hispanic immigrant children: A service learning approach. Journal of Latinos and Education, 6, 177-189. doi:10.1080/15348430701305028

Boss, P. (1999). Ambiguous loss. Learning to live with unresolved grief. Cambridge, MA: Harvard University Press.

Butin, D. W. (2006). The limits of service-learning in higher education. Review of Higher Education, $29,473-498$. doi:10.1353/rhe.2006.0025

Carney, T. M. (2004). Reaching beyond borders through service learning. Journal of Latinos and Education, 3, 267271. doi:10.1207/s1532771xjle0304_5

Charmaz, K. (2006). Constructing grounded theory. A practical guide to qualitative analysis. London, England: Sage.

Chattaraman, V., Rudd, N. A., \& Lennon, S. J. (2005). Identity salience and shifts in product preferences of Hispanic consumers: Cultural relevance of product attributes as a moderator. Journal of Business Research, 62, 826-833. doi:10.1016/j.jbusres.2008.04.002

Chavez, L. R. (2008). The Latina/o threat: Constructing immigrants, citizens, and the nation. Stanford, CA: Stanford University Press.

Cohen, J., \& Kinsey, D. (1994). 'Doing good' and scholarship: A service learning study. Journalism Educator, 49(4), 414.

Conti, C. (2011). 'Is anybody listening?' Questioning the local bond between LPFM programmers and their audience. Journal of Communication Inquiry, 35, 20-36. doi:10.1177/0196859910369553

Deans, T. (1999). Service-learning in two keys: Paulo Freire's critical pedagogy in relation to John Dewey's pragmatism. Michigan Journal of Community Service-Learning, 6, 15-29.

De Leon, N., \& Kirby-Stokes, C. (n.d.). Western Kentucky University service-learning faculty handbook. Bowling Green, KY: WKU Center for Community Partnerships. Retrieved from http://www.wku.edu/alive/documents/publications/ faculty_handbook_servicelearning.pdf

de los Ríos, C. V., \& Ochoa, G. L. (2012). The people united shall never be divided: Reflections on community, collaboration, and change. Journal of Latinos and Education, 11, 271-279. doi:10.1080/15348431.2012.715507

Dewey, J. (1938). Experience and education. New York, NY: Collier.

Emerson, R. M., Fretz, R. I., \& Shaw, L. L. (2011). Writing ethnographic fieldnotes. Chicago, IL: University of Chicago Press.

Feagin, J. R., Orum, A. M., \& Sjoberg, G. (Eds.). (1991). A case for the case study. Chapel Hill: University of North Carolina Press.

Flourney, C. (2007). Doing learning: Investigating reporting and service learning. Journalism \& Mass Communication Educator, 62, 47-61. doi:10.1177/107769580706200105

Freire, P. (1973). Education for critical consciousness. New York, NY: Continuum.

Hondagneou-Sotelo, P., \& Raskoff, S. (1994). Community service-learning: Promises and problems. Teaching Sociology, 22, 248-254. doi:10.2307/1319139

Kawaja, J. (1994). Process video: Self-reference and social change. In P. Riaño (Ed.), Women in grassroots communication: Furthering social change (pp. 131-148). Thousand Oaks, CA: Sage.

Kelley, G. (2012). Service-learning: An action oriented program evaluation. Retrieved from ProQuest Dissertations and Theses. (UMI No. 3595230).

Korzenny, F. (2012, October 8). Mobile Latinos [Web log post]. Retrieved from http://felipekorzenny.blogspot.com/ 2012/10/mobile-latinos.html

Len-Ríos, M. E., \& Perry, E. L. (2009). Assessing cross-cultural learning and the effects of personality and negative attitudes on journalism students' knowledge. Journalism \& Mass Communication Educator, 64, $273-286$. doi:10.1177/107769580906400304

Martínez, M. A., Cortez, L. J., \& Saenz, V. B. (2013). Latino parents' perceptions of the role of schools in college readiness. Journal of Latinos and Education, 12, 108-120. doi:10.1080/15348431.2012.745402

McAnany, E. (2012). Saving the world. A brief history of communication for development and social change. Chicago, IL: University of Chicago Press.

Mills, C. W. (1959/2000). The sociological imagination. Oxford, UK: Oxford University Press. 
Mitchell, T. D. (2008). Traditional vs. critical service-learning: Engaging the literature to differentiate two models. Michigan Journal of Community Service-Learning, 14, 50-65.

Novek, E. (1999). Read all about it: Using civic journalism as a service-learning strategy. In D. Droge \& B. Ortega Murphy (Eds.), Voices of strong democracy: Concepts and models for service-learning in communication studies (pp. 145-154). Sterling, VA: Stylus.

Nguyen, M. T., \& Gill, H. (2010). The 287(g) Program - The Costs and Consequences of Local Immigration Enforcement in North Carolina Communities. The Latina/o Migration Project (p. 48). The Institute for the Study of the Americas: The University of North Carolina at Chapel Hill. Chapel Hill, NC.

Office of Institutional Research and Assessment. (2013). Table 2: Students by Level, Race/Ethnicity, and Sex, Fall 2013. Fact Book 2013-2014. University of North Carolina at Chapel Hill. Retrieved from: http://oira.unc.edu/files/2014/ 09/fb2013_2014.pdf

Panici, D., \& Lasky, K. (2002). Service-learning's foothold in communication scholarship. Journalism \& Mass Communication Educator, 57, 113-125. doi:10.1177/107769580205700202

Paulin, L. (2011). Winning and losing in North Carolina-Cultural citizenship struggles and lessons for Latino newspapers. Latino Studies, 9, 198-218. doi:10.1057/lst.2011.22

Podkalicka, A. (2009). Young listening: An ethnography of YouthWorx Media's radio project. Continuum: Journal of Media and Cultural Studies, 23, 561-572. doi:10.1080/10304310903015704

Reis, R. (2010, April 5). Strengths and limitations of case studies. Tomorrow's Professor. Retrieved from http://cgi. stanford.edu/ dept-ctl/tomprof/posting.php?ID=1013

Rosaldo, R., \& Flores, W. V. (1997). Identity, conflict, and evolving Latino communities: Cultural citizenship in San Jose, California. In W. V. Flores \& R. Benmayor (Eds.), Latino cultural citizenship: Claiming identity, space, and rights (pp. 57-96). Boston, MA: Beacon.

Scatanburlo-D'Annibale, V., \& McLaren, P. (2004). Class dismissed? Historical materialism and the politics of 'difference.' Educational Philosophy and Theory, 36, 183-199. doi:10.1111/j.1469-5812.2004.00060.x

Sperling, R. (2007). Service-learning as a method of teaching multiculturalism to White college students. Journal of Latinos and Education, 6, 309-322. doi:10.1080/15348430701473454

Stake, R. (1995). The art of case study research. Thousand Oaks, CA: Sage.

Suarez-Balcazar, Y., Balcazar, F., Taylor-Ritzler, T., Portillo, N., Rodakowsk, J., Garcia-Ramirez, M., \& Willis, C. (2011). Development and validation of the cultural competence assessment instrument: A factorial analysis. Journal of Rehabilitation, 77, 4-13.

University of North Carolina, General Assembly (2007). University of North Carolina System: Enrollment and Changing Diversity for the State. Chapel Hill, NC.

Unwin, T. (Ed.). (2009). Information and communication technology for development. Cambridge, UK: Cambridge 615 University Press. 
Copyright of Journal of Latinos \& Education is the property of Taylor \& Francis Ltd and its content may not be copied or emailed to multiple sites or posted to a listserv without the copyright holder's express written permission. However, users may print, download, or email articles for individual use. 